Comparative Philosophy Volume 6, No. 1 (2015): 169-184

Open Access / ISSN 2151-6014

www.comparativephilosophy.org

CONSTRUCTIVE ENGAGEMENT DIALOGUE (1.3)

\title{
REPLIES TO BRONS AND MOU ON WANG CHONG AND PLURALISM
}

\author{
ALEXUS MCLEOD
}

I would first like to thank Lajos Brons and Bo Mou for their thoughtful and detailed comments and criticisms on my work on Wang Chong, and on Wang Chong as a theorist in general. Wang has not received the attention he deserves from philosophers, and I am glad to see this step forward in the pages of Comparative Philosophy. This is a long overdue conversation. The philosophical investigation of Wang Chong's work is sorely needed, and already we see in this engagement some of the possible fruits of this investigation. I will focus my comments on responding to a few of the very insightful comments and criticisms of Brons and Mou. Since their remarks are included in this issue of Comparative Philosophy, I will for the most part allow them to speak for themselves, and refrain from reconstructing their positions, instead focusing on response.

\section{A Brief Methodological Note}

My own methodological considerations when constructing interpretations are textual and conceptual. While there are numerous methods of interpretation in the history of philosophy, and even more in comparative philosophy, I tend to interpret figures in the history of philosophy (whether Chinese, Western, Maya, or other) using these two considerations. The textual question is this: how can we make sense of a text in the most charitable way possible, given conceptions of rationality, consistency, and justification that the authors and people in their time would have found plausible? This may be somewhat problematic, given that we have to simply assume that the thinkers who wrote the text(s) in question held certain conceptions of rationality, etc. where they are unclear from the historical context. Thus any interpretation comes with an implicit conditional caveat: if thinker $\mathrm{x}$ shared my/our conceptions of rationality, consistency, etc, then this interpretation can explain what is written in

MCLEOD, ALEXUS: Assistant Professor of Philosophy, Colorado State University, USA. Email: alexus.mcleod@colostate.edu 
thinker x's text. And even this cannot ensure that one has it right. As I point out in the original paper on Wang, one can only ever arrive at an interpretation that is maximally consistent with a text, but there will be other equally consistent yet mutually exclusive interpretations. A text alone, and perhaps even historical context, cannot privilege one interpretation over another (though it might rule some out).

The conceptual aspect of interpretation is helpful in helping to break stalemates. Thus, the conceptual question I ask in constructing an interpretation is this one: does the proposed interpretation work well as a theory of the topic in discussion (assuming our own conceptual standards)? Can it contribute to our own understanding of the topic? Can it advance contemporary debates about the topic? This question then is both conceptual and pragmatic to some extent. Thus, whether an interpretation is a philosophically desirable one has to do with whether it is faithful to (in terms of maximal consistency with) the text, as well as whether it offers us a useful theory in terms of advancing our own understanding of a topic. This is, I think, the best way of balancing the two purposes of the history of philosophy - to both understand what the views of historical philosophers were, as well as to learn from them and use them to help better understand key topics such as truth, knowledge, right action, etc.

This methodological structure, I think, is behind some of the differences between the views of Brons and Mou and myself on Wang Chong's theory of truth. This is moreso in the case of Brons than that of Mou, but nonetheless it is useful to clarify these methodological points at the outset, which I will refer back to below.

\section{Brons' Objections, Kinds of Pluralism, and "Quasi-Pluralism”}

Brons raises four objections to my interpretation of Wang Chong as a pluralist. 1) Symmetry problems concerning the shi-xu (實虛, “truth and falsity”) opposition, 2) skepticism about translation of terms as truth terms, 3) doubts about textual evidence for the substantivity of shi (是) and ran (然) as truth-related properties, and 4) seeming inconsistencies in terminology applied to domain in Wang's essays in the Lun-Heng.

\subsection{Symmetry concerns}

Brons' concerns about the symmetry of the shi-xu relationship are driven by a particular conception of pluralism he adopts, his definition (TP) and the related (TP*) $[134]^{1}$. This conception as a general definition of pluralism about truth is very problematic, and needs to be discussed here.

I'm not sure that all kinds of truth pluralism can be captured by a formal definition of the kind Brons offers with his (TP). There are a number of vastly different varieties of pluralism, from Crispin Wright's "platitudes" approach, to Mou's "substantive perspectivism" and even Gila Sher's pluralistic correspondence

\footnotetext{
${ }^{1}$ The page numbers of Brons and Mou's citation references in the current issue are given in bracket parentheses.
} 
theory. Even a deflationist of a certain stripe might qualify as a "pluralist" about truth in some sense. So when we limit the scope of pluralist theories as drastically as Brons does to a definition like (TP), we rule out a number of theories that are pluralist in motivation and outcome as "genuine" pluralisms. Crispin Wright discusses this kind of thing in (Wright 2013). Being as charitable as possible, we should define pluralism as not as requiring a particular and very specific logical structure of the kind Brons insists on, but as any theory capturing a more general description that makes sense of the pluralist motivation and outcome.

Indeed, the way Brons defines pluralism seems to make pluralism by definition susceptible to problems commonly raised for pluralist theories, such as that of mixed conjunctions, substantiveness of the primary truth property, univocality of truth, etc. A pluralist will not be able to modify a pluralist theory so as to eliminate these problems, because most modifications that would dissolve these problems would give us a theory no longer consistent with (TP), and thus, on Brons' account, no longer a pluralist theory of truth. Surely pluralism should not be this narrowly construed. It looks like what Brons has defined with (TP) is a particular type of pluralist theory of truth, not a general definition of truth pluralism. I agree with Brons completely that Wang Chong's pluralism does not fall under (TP)—-where I disagree with him is that this shows that Wang Chong's view is not a kind of pluralism about truth.

Even in his "weaker" statement, Brons draws too narrow a boundary for pluralism. He says: "In a genuine pluralism, one would expect a general(ized), domain-transcending concept to behave in ways similar to its domain-specific counterparts. If domain-specific concepts come in contradictory pairs, then one would expect the general(ized) concept to do the same. If the apparent general(ized) concept behaves differently (in this respect) than the domain-specific concepts, then most likely it is not a general form thereof... and one is probably not dealing with a genuine pluralism.” [139]

This is certainly too strong a claim. If we restrict pluralist theories to those that take general concepts of truth and falsity to correspond to domain-specific "counterparts", many pluralist theories are ruled out, including Crispin Wright's (a second-order property cannot be counterpart in this way to a domain-specific property, in that it plays the same role within domain the truth property does in general), the "correspondence pluralism" of Gila Sher, Terrence Horgan, and others, Wang's pluralism as I've defined it, and others. Crispin Wright indeed discusses this problem in his recent paper "A Plurality of Pluralisms". He argues there are "four basic modes" of pluralism, rather than an overarching (and very narrowly defined) form as Brons offers in (TP). ${ }^{2}$

This is why I am somewhat sympathetic to Gila Sher's version of "pluralism". She advocates a correspondence theory that is nimble enough to make sense of different kinds of correspondence, or different ways that statements might correspond with the world. Sher thus accepts the pluralist motivations and intuitions, without

\footnotetext{
2 "it's helpful to think in terms of four basic modes of pluralism [...] and then there are sub-types under those modes." (Wright 2013, 126)
} 
abandoning the idea that a specific kind of property (specifically, a correspondence relation) is at the basis of truth. I don't think this is a kind of quasi-pluralism or "nongenuine" pluralism, but rather a legitimate pluralism that gets at really just what the pluralist in general is after. The intuition the pluralist in general wishes to capture is that there should be different ways we understand how this relationship between statements and whatever is construed given different domains of discourse, without giving up on a single and univocal concept of truth. More "traditional" pluralist theories of truth represent one way of doing this (perhaps like Brons' definition of pluralism, although I think it's still too narrow), and other pluralist-inspired views like Sher's and, I think, Wang Chong's, represent other ways of doing it. Wang's view is not consistent with (TP), but it is a kind of pluralism about truth.

Thus one problem here is that Brons takes my position to hold that "shi and ran are two different ways of being SHI, and SHI is, therefore, general T-truth in (TP), [and] fei and fou, as, respectively, not-shi and not-ran must be two different ways of being not-SHI." [139] Shi 是 and ran 然, however, are not "two different ways of being shi 實". They are the same way of fitting shi 實, the general truth property. If $s h i$ 實 is having the properties we do and should seek, having shi 是 or ran 然 is to have the general truth property $s h i$ 實.

$S h i$ 實 is not a general truth property of which shi, ran, etc. are domain specific associates or counterparts. Wang's pluralism doesn't work like that, which is why I likened it more to Wright. Rather, it is the description of the shi 實 concept that determines which properties are picked out in whatever domains. These properties picked out in domains are NOT truth properties in any sense-only shi 實 is a truth property. They are simply selected by meeting the description of $s h i$ 實 - that is, they are properties we do and should seek. What makes them shi 實 is that we do and should seek them, and this is domain independent. What changes with domain is NOT, then, some property that instantiates or is functionally related at all to truth, or plays the truth role, or anything like that. What changes is which properties we do and should seek. That is what is sensitive to context. If truth is fundamentally normative and descriptive, then the descriptions (what we do seek) and normative statements (what we ought seek) will change by domain. What determines why there is such a change is not explained by the concept of truth, but no theory of truth does offers this (nor should it). When we call the theory of relativity true, the concept of truth or property the statement has that explains its truth has no role in the explanation of what makes the theory true. If we take correspondence for example, then what makes a statement true is that it corresponds with states of affairs. This will not, however, tell us why this theory (the theory of relativity) and not some other does in fact correspond with states of affairs. That is a question about the world, not about the relationship between language and the world. This is asking too much of any theory of truth, not just the pluralist (or Wang's pluralist) theory.

Brons is also worried about what he takes to be the lack of an opposite concept to $s h i$ 實 on my interpretation of Wang, as I define $x u$ 虛 as "merely apparent truth". Brons is right in his claim that Wang does not concern himself with the construction 
bu shi 不實 ("not true"), but the reason for this, as I explain in my original article, is that there is a class of statements (yan 言) we are simply not concerned with because no one would ever (so Wang thinks) likely assert them as true. Given that truth is already fundamentally normative ( $s h i$ 實 statements are those with properties we do and should seek), the only statements we have any reason to appraise for shi-value are those we are in some way inclined to think may have such shi-making properties. And not all statements are this way. Wang Chong is simply not interested in appraising all possible statements for their truth value, and his understanding of $x u$ 虛 demonstrates this limiting of the domain of appraisable statements. While this may strike some as odd, it shouldn't. Contemporary analytic philosophers also limit the scope of truth-appraisable statements, even though they seem to share a broad intuition that any statement making an assertion should take a truth value. This is the intuition that led to the origins of the analytic tradition in attempts to secure a truth value for statements like "the present King of France is bald", and sustains it still in attempts to make sense of truth paradoxes. While we tend to be uncomfortable with the notion that an statement with assertoric content can lack a truth value, Wang Chong and other early Chinese thinkers seem to have no such worry. This is the reason such truth paradoxes and worries about truth values in cases of reference failure did not tax early Chinese thinkers. Wang would have placed such statements in the category of those that simply are neither shi nor $x u .^{3}$

There is no reason to talk about or consider statements that either no one would ever accept as true or no one could ever accept as true. This is part of the result of normativity being basic on Wang's account. Indeed, the fact that Wang talks only in terms of $x u$ rather than $b u$ shi further strengthens my interpretation of him as holding that normativity is basic. We should expect just this if he does so. Non-attractive propositions are ones we need not worry about, if we're already working with a prior conception of what we ought to be seeking.

\subsection{Translation concerns}

Brons' suggested translation of shi 實 as 'objective' in order contrast it with $x u$ 虛 as merely apparent truth or mere attractiveness is flawed. First, it is unclear what is meant by 'objective', and how Brons envisions it as different from 'truth'. Is objective "the way the world is independently of how you perceive it to be?" If that's the case, one may argue that it is not different from truth. It certainly sounds a whole lot like some kind of correspondence property. So if it's not truth it can't be this. What else might it be? Of course, there are many possibilities for defining a concept of objectivity as different from one of truth, but Brons does not offer one here. But this seems necessary if we are to determine wither 'objective' is a better translation of $s h i$ 實 than 'truth'. Brons writes [141]: “The notions of objectivity and truth are

\footnotetext{
${ }^{3}$ As an interesting historical aside, this is a category that did not particularly bother most classical Indian philosophers either, who made room for assertions with truth values other than true or falseincluding both true and false, and neither true nor false.
} 
closely related, but sufficiently different not to be the same (kind of) notion or to stand in the relation of general form $\mathrm{T}$ and domain-specific $\mathrm{A}$ in (TP), and therefore, do not suggest pluralism." There are a number of problems with this. First, how is Brons' undefined concept of objectivity different from truth, especially as he first claims they are closely related? And if it is closely related, even if not identical to truth, why would there not simply be an objectivity-pluralism suggested by such a position, in which some general concept of objectivity plays the general truth role in Brons' (TP)? Brons' (TP) is defined formally, so it does not specify which concepts have to be attached to the formal relations involved. Why couldn't an "objectivity pluralism" fit that exact same formal definition?

Another difficulty is that much of Brons' argument in this section is based on the fact that the concepts in question, particularly shi 實, can be understood differently than I understand them. And I don't dispute this. I don't take my argument to be a necessitating argument, in which the conclusion is entailed in terms of strict validity by the premises. But no interpretive argument can ever achieve this. I take my reading of Wang to shed light on what he may be doing, and making sense of the way he uses concepts like shi and $x u$ that would constitute an interesting and innovative theory. The methodological considerations I outlined in section 1 above guide my interpretation and argument. There is certainly much that goes into this (or any interpretation) beyond what we are given from the text alone. From what a text explicitly says we are not entitled to any interpretive conclusion other than a rephrasing of exactly what is said in the text. The only interpretative conclusions that can be demonstrated with certainty (and perhaps not even these, given issues of meaning suggested by Brons) are those that simply repeat what the original author said. Kong Zi said 克已復禮為仁也, in the Lun-Yu 12.1. What did he mean by this? He meant that 克已復禮為仁也. In any interpretation (and translation is also necessarily interpretation) we attempt to "fill in the lines," to make sense of what a text did not say by considering what it may have meant, or by trying to figure out what kind of consistent view or system might be suggested by what is said. And to do this we have to appeal to history and tradition, but also to conceptual concerns.

\subsection{Concerns About Substantivity}

In section 2.3 Brons considers the possibility of shi 是 and ran 然 as simply terminological differences attached to domain, similar to the Japanese 'aru' and 'iru' which both refer to being, but one in the case of animate and one in the case of inanimate things. If shi and ran are only different ways of referring to the same property in different contexts or domains, however, then this is even worse for my view than Brons suggests. This would make Wang's views not a "quasi-pluralism", as Brons argues, but no kind of pluralism at all. It would be akin to my calling truth 'truth' on Mondays and Wednesdays, and 'alcatraz' on Tuesdays and Thursdays, just as a quirk of term usage. When I say on Monday "it is true that Mars is the fourth planet from the Sun" I mean the same thing as I do when I say on Thursday "it is 
alcatraz that Mars is the fourth planet from the Sun", at least insofar as truth is concerned (setting aside the statement about what day it is that I also make). The statement "Mars is the fourth planet from the Sun" has the property of being alcatraz when it has the property of being true - there is only one property involved here and I am simply referring to it using different terms whose usage corresponds to differences having nothing to do with truth properties. So there is no pluralism about truth any kind going on here. This would be the case with Wang if his distinction between shi and ran were akin to the aru/iru distinction.

Brons, however, argues that there is insufficient textual or other evidence to think that the shi/ran distinction is any more substantive than that of iru/aru. Brons argues that the most we can gain from anything said by Wang is that "justification depends on evidence, not that truth (itself) depends on evidence or that evidence makes statements true" [143] Brons is certainly right about this. But there are a couple of problems with applying this to my interpretation of Wang. First, as I explain in my original article in this journal on Wang's theory of truth ${ }^{4}$, everything Wang says about shi and ran in the Lun-Heng is consistent with another less theoretical interpretation in which the differences between the terms are simply stylistic or based in usage (though it is much more likely to be the former rather than the latter in Wang's case). Nowhere in the paper do I attempt to demonstrate that my interpretation of Wang is the only possible one consistent with the text. Rather, it is one possible interpretation, with significant implications, illuminating a number of features of Wang's overall project in the Lun-Heng, even independently of what it contributes to contemporary debates. Part of my argument here is that it turns out that Wang is doing something really philosophically interesting and innovative if we read him in the way I do, while if we take his distinction between shi and ran to be due to stylistic or usage issues, his discussion of them appears as far more pedantic, of questionable import, and puzzling (why would anyone spend so much time and effort going on about that?). Since part of the task of the interpreter is to make a thinker explicable and render them as interesting or coherent as possible, it seems to me that we ought to err on the side of the more interesting or illuminating interpretation when there are not disqualifying considerations over some less illuminating interpretation.

A second problem is that if we have no particular textual justification for reading Wang as adopting a robust theory of truth rather than a primitivist stance, aren't we in the same position for almost every philosopher who doesn't explicitly talk about truth in such a way that makes it clear he or she rejects primitivism?

Brons says [143]: "The fact that [Wang]—in a book in which truth plays such a central role - never even hinted at what truth is or what shi 是, ran 然, or shi 實 mean strongly suggests that he (implicitly!) considered truth to be primitive." I don't think this follows at all. If it does, should we take this to show that anyone who does not explicitly engage in debate concerning the meaning of the predicate 'is true' and the property/properties picked out by that predicate is a primitivist about truth? It may then turn out that almost every philosopher in history was a primitivist.

\footnotetext{
${ }^{4}$ McLeod 2011, 53, note 33, also discussed by Mou in his article in this issue [162-163].
} 
Of course, I must concede to Brons that Wang could not have developed a pluralist theory of truth as an explicit position meant to compete with other theories or as itself intended as a contribution to early Chinese thinking about truth. Much of Wang's view, if I am right about it, must have been implicit, in a way similar to how some kind of dualist theory of mind is implicit in the views of a person who argues for or otherwise accepts life after death.

\subsection{Terminological Domain Inconsistencies}

Of the four difficulties Brons raises, I think the last one is the toughest for my position. The other three difficulties largely stem from a particular way of envisioning pluralism and particular choices methodological differences about translation and interpretation that we might simply (and perhaps have some reason to) reject. The fourth difficulty raised brings up a problem that comes right from the text, however. Brons is right, Wang Chong does vacillate in his use of this terminology, and is not completely consistent in applying it in consistent domains. Wang's consistency often leaves much to be desired, as noted by a number of interpreters, and one of the key questions in attempting to understand the Lun-Heng as a whole is: what accounts for this inconsistency? A less charitable option is that offered by Nylan - that Wang was simply not careful or more concerned with the arguments of particular essays and winning immediate debates than with overall consistency. I think there is little evidence for this, and am not sure why we should be inclined to extend so little charity to Wang, given that there are a number of other explanations. One that I offered in an article on the Wen-Kong chapter ${ }^{5}$ is that Wang was concerned primarily with method and not with positions, and so particular positions were of relatively little concern to him - he was simply demonstrating the operation of his method of appraising statements and teachings (yan 言), using wen 問 (questioning) and nan 難 (challenging).

Another real possibility is that Wang wrote the essays of the Lun-Heng at different stages in his career, and had different views, arguments, understandings of concepts, and use of terminology. Indeed, if the Lun-Heng is a compilation of Wang Chong's works, as Forke and others have offered decent evidence for (and its organization is quite strange for a single work), we should expect such divergence. Classics scholars and specialists in Ancient Greek philosophy exercise themselves over the issue of the substantive differences between Plato's views and concepts in his early, middle, and late periods of intellectual production. We cannot assume that Plato held the same views, made the same arguments, and used terminology in the same ways throughout his entire productive life. Who among us does this? Yet oddly, for some reason there is a much greater tendency among scholars of Chinese philosophy to assume the coherence of clearly collected works of an individual

\footnotetext{
${ }^{5}$ McLeod 2007.
} 
scholar, or even collections of multiple scholars, such as early texts like the Lun-Yu or the Dao-De-Jing.

Yet this is not the problem with Wang. As Brons points out, the very texts I use to establish this domain difference of terms like shi and ran are inconsistent, and sometimes use the terms together, in particular in the shi-fei-zhi-shi 是非之實 construction Brons discusses here. This is indeed a difficulty, and on my account of Wang's pluralism, if shi 實 is an endorsement of the properties we do and should seek, then shi-fei-zhi-shi 是非之實 would have to be understood in a less than literal way. $S h i$ 是 and $f e i$ 非 don't literally have a shi 實, as the construction suggests. They can't, because they are not themselves statements (yan 言). Instead this would have to refer to the "truth about shi and fei" - the truth about whether statements have the properties we do and should seek, with reference to a particular domain. No doubt this is an awkward, and perhaps even flawed usage. But it's far from clear that this construction rules out the kind of truth pluralism I attribute to Wang. Even though pluralism renders this construction more difficult, there is a tradeoff, in that it makes Wang's other moves concerning the difference between these terms in different contexts, as well as his different usage of shi 實 and the other truth-like terms much more explicable. Good (or at least charitable) interpretation aims to interpret a thinker's positions as being as consistent or as strong as possible. Given Wang's clear tendency to be quick and uncareful, it shouldn't surprise us that there may be some difficulties engendered by his views. It's just a matter of how much awkwardness and inconsistency we're comfortable with attributing to him.

\subsection{On "Quasi-Pluralism"}

Brons' own suggestions for interpreting Wang on his "truth-like" concepts is an interesting one, and should be developed in greater detail. Ultimately the strength of each interpretation will depend on how well it makes sense of the whole of the LunHeng's claims on the topic of truth and "truth-like" concepts-how much is rendered intelligible and sensible by each theory. One way of understanding my interpretive claim is that the truth pluralism I attribute to Wang makes the most sense as a whole of the greatest percentage of what Wang says about these truth-like concepts of available theories--although of course Brons is right that it doesn't make sense of everything Wang says in Lun-Heng, and no interpretation will be able to do this if it turns out Wang was inconsistent in any way concerning his views about truth. If Wang was inconsistent in some way, then no interpretation that adequately accounts for all of what he says will leave him $100 \%$ consistent, and no $100 \%$ consistent interpretation will be able to account for everything he says. I think my account is ultimately a better explanation than alternatives, but this remains to be seen. It may be the case that some other interpretation makes better sense of Wang's words on the topic, but I don't see anything so far that rules out my interpretation. I encourage Brons to pursue development of the interpretation he suggests in the final section of 
his comments, which I think can be useful as a contrast to my own interpretation and that of Bo Mou in understanding the views of Wang Chong on truth.

\section{Mou's "Substantive Perspectivist" Alternative}

Mou offers a fleshed out alternative account (developed in his comments here as well as in previous work) that aims to explain not only more of the textual evidence from the Lun-Heng but also to have greater conceptual continuity and historical connection with other early Chinese thinkers than my own account. These indeed would be strong reasons to accept such an interpretation over my own.

Mou, unlike Brons, agrees with me in reading Wang Chong as a pluralist. Mou's account of Wang is somewhat close to my own, in that he takes shi 實 to be an expression (or elaboration) of a basic and abstract truth concept.. Mou's description of the "pre-theoretic" notion of "the way things are" seems to me close to my consideration of the descriptive part of my interpretation of Wang's concept of truth, possession of the properties people do seek (the normative part being possession of the properties people should seek). Mou disagreements with my interpretation come at different points. In particular, Mou rejects the idea that truth for Wang Chong should be thought of as a second order property.

Mou's central argument against my interpretation of the truth property as second order is that it relies, he says, on a pre-theoretic first order understanding of truth, which is the primary sense of truth terms such as $s h i$ 實. My reading fails, he argues, to offer an account capturing this basic and primary sense of truth Mou's reading of $s h i$ 實 is in keeping with a pre-Han folk understanding of the term, which he (rightly, in some ways) claims that my interpretation of Wang Chong's use is not in line with. This pre-theoretic understanding of truth Mou refers to, captured in his definition (ATNT), has to do with an intuitive sense of capturing "the way things are". This seems to me nearly identical to what is often called the "correspondence intuition", that many (inflationary) theorists, correspondentist, coherentist, pluralist, or other, take as central to the concept of truth. A correspondence intuition of course does not entail correspondence theory, because the requirement that truth in some way be an expression of the way things are can be theoretically represented in a number of different ways, correspondence theory only being one of them. Thus one can eschew correspondence theory and still accept the correspondence intuition. Indeed, such an intuition is seen as one of the hallmarks of "inflationary" theories of truth. If the truth property is substantive, then one of the things it had better do is ensure that its bearer in some way represents or matches "the way things are". Otherwise, it looks like we are dealing with some property other than a truth property. We might argue that correspondence in this weak sense is one of the things that makes truth what it is, and is a basic and necessary feature for any substantive theory of truth. In fact, I agree with Mou that something like the correspondence intuition or his ATNT is indeed basic and at the core of the general concept of truth, including in Wang's account. My main difference with Mou concerns where in the structure of Wang's theory this intuition is accounted for. 
Mou presents four problems for my interpretation of Wang on truth: 1) the second-order property I interpret Wang as associating with shi 實 seems to include a prior notion of truth already within it, more fundamental than the second-order property itself. That is, if there is some second-order property of the kind I suggest, it must be derivative rather than primary for this reason, and thus cannot capture the basic notion of truth for Wang Chong (or in general); 2) My interpretation of truth in Wang Chong diverges radically from an earlier understanding of the concept that is more in line with Mou's reading of it as representing a basic, pre-theoretical understanding of truth; 3) In Warring States thought, Mou argues, theories of truth are in general meant to elaborate the folk understanding of truth ( $s h i$ 實) mentioned in \#3, and my interpretation of Wang's understanding of truth is not in keeping with this; 4) I make the claim in the paper that Wang's position is that the normativity included in the second-order property of $s h i$ 實 is explanatorily basic, even though I don't provide the necessary argument for this.

\subsection{Historical Context and the Folk Understanding of Truth}

I will attempt to respond to Mou's objections 1-3 at once, as I see these surrounding similar considerations, and possibily as variants of one larger objection. I think that the second-order concept of shi 實 I attribute to Wang does capture an understanding of truth that pre-existed Wang Chong in early Chinese thought, and also captures a number of "pre-theoretical" intuitions about truth.

Mou argues that my interpretation of Wang lifts him out of his historical context, and doesn't provide enough continuity between the concepts and theories of other early Chinese philosophers. I completely agree with Mou that my readings of shi 實 and other concepts in the Lun-Heng are very different from traditional understandings of them in the Warring States and even in the Han. They are different, but they are not wholly disconnected from earlier theories or understandings. I disagree with Mou that the discontinuity between Wang's view of truth as I understand it and earlier views of truth in the Chinese tradition constitutes a weakness for my interpretation. Wang was a notoriously idiosyncratic thinker, and his divergence from accepted norms went even to the level of his literary style, which was radically different from that of his contemporaries ${ }^{6}$. Part of the reason for the relative neglect of Wang's philosophical work was its perceived strangeness, because it was so different than other intellectual productions of its time. Wang (like Zhuang Zi) was an unusual, nontraditional, and unrepresentative thinker in many ways. This is not to say that there was no continuity between his ideas and those of his contemporaries and earlier Han and Warring States thinkers. But there was massive divergence as well.

Mou argues [162] concerning my attribution of a second-order concept of shi to Wang that:

\footnotetext{
${ }^{6}$ Michael Nylan discusses the divergence of Wang's style from accepted norms of his time in (Nylan 1997).
} 
"(1) what is missed is the real basis or root and due foundation whose central point is captured by people's pre-theoretic understanding of truth concerning the first-order nature of truth and whose various aspects and layers have been, and can be further elaborated from distinct already-presented or coming perspectives in treating the philosophical issue of truth; (2) some derivative second (or higher) order property is arguably mis-located at the primary basis, as it is a part of a variety of (normative or prescriptively identified) explanatory roles or functions that are essentially and eventually played by the already understood concept of truth as captured by people's pre- theoretic understanding of truth."

While I agree with Mou that Wang's concept of shi 實 was intended to be an elaboration rather than a radical revision of the folk understanding of truth, I think that this understanding can be captured by a second-order concept (or many other kinds of concept), and also that second-order concepts can be basic in a theoretical sense.

$S h i$ 實 is an interesting term in early Chinese thought in part because of the variety of ways it was used and understood. It almost certainly shifted its meaning(s) between the early Zhou and the later Warring States period, often used in early texts to signify "fruit" (literally, of a plant), or the related concept of "result", In other places, it is used in a sense suggesting "substance", which is what leads to its understanding as "ground" or "reality"-it is in this sense it is likely meant in the Xun-Zi's considerations of the distinction between name (ming 名) and shi. We do see the ming-shi consideration made in texts throughout the Han dynasty, including after Wang's time in Xu Gan's Zhong-Lun, but Wang himself is not interested in this distinction. He uses shi in distinction to $x u$ 虛 most regularly, suggesting that he is using a concept that, while almost certainly related in some way to Xun Zi's concept of $s h i$ 實 and others, is quite different and non-continuous with theirs. At the same time, Wang's use of shi and $x u$ and particular application of them to statements (yan 言) differs from the uses of earlier thinkers in the Warring States, who apply shi to any entity, as any entity can have a purpose, value, or substance.

I don't think it's the case that there was a single agreed-upon usage of $s h i$ 實 in Han and Pre-Han texts, and it is one of the most diversely understood concepts of early Chinese thought. We see very different understandings of it in the Xun-Zi and the Meng-Zi, for example, and different understandings than these in early Han texts such as the Huai-Nan-Zi. In the later Han, Xu Gan's use of shi is radically different from any of these earlier ones, even though he considers some similar issues such as the ming-shi distinction. Shi, like other contentious terms and concepts such as xing 性 (“nature”), ren 仁 ("humanity”), or dao 道 (“way”), is understood in a multitude of different ways in early China, and Wang's use, I argue, is a highly idiosyncratic one.

\footnotetext{
${ }^{7}$ Even texts such as the $L u n-Y u$ and the $L i-J i$ in multiple senses, "fruit" as well as "fullness", perhaps a literal and allegorical sense of 'fruit'. Thus in the Lun-Yu 9.22 Kong Zi discusses 秀而不實者 (“blooms with no fruit"), while in the $L u n-Y u$ 8.5 Zeng Zi describes a friend as 實若虛 (“full but seeming empty").
} 
One way of understanding a relatively general use of $s h i$ 實, then, is as itself an evaluative term that is fundamentally open. That is, it may be fundamentally "pluralistic" at even the most basic level, in its folk conception, in the same way that a term like 'result' or 'goal' may be. That is, the term suggests a general concept, but can also be used to refer to a particular thing that fits a general description. "The result of crime is suffering", for example. 'Result' here is something general-the state or thing that is caused or otherwise brought about primarily by some actionwhile at the same time it refers in this case to suffering, as the particular result of crime. Each action has a result. And our understanding of an action's result, we might think, is more basic than our understanding of a particular result of a particular action, even if we come to this more general concept from our observation of the world, of actions and their particular results. The basic concept is the general concept that we derive from observation of particulars. Once we have such a concept, however, it is this concept that we use primarily, both temporally and conceptually. What is it to have the property of "being a result"? To have the property of being a state caused by some action. Being the effect of some action is based on being the effect of this particular action (i.e. crime). While this is perhaps not a second-order property, it is not far removed, in that it is a general property that is arguably more basic than the specific property of 'being a state caused by crime'. This latter property is that of "suffering", not that of "being a result". Thus when we are concerned with the general concept of the "result", we are already dealing with something either general or higher-order. In fact, a higher-order view may simply be one way of expressing the generality of a concept.

The concept of shi 實, I think, given the early uses of the term, was always thought of as a general term with its property picked out by the particular object under discussion. Wang's application of shi 實 to statements (yan 言) in particular thus naturally suggests a kind of pluralist approach to truth, with shi operating as the general truth concept. But if we take shi in its sense as 'fruit' or 'result', a basic and general concept, we can see how Wang's conception, even though indeed divergent from earlier conceptions, does not radically break with earlier understandings of it in the tradition. That is, my reading of Wang does not attribute to him a view that comes out of the blue seemingly from nowhere. We see its roots in earlier Chinese thought. It would be odd, I think, to read Wang as completely sharing common understandings of concepts such as shi 實, given both his own admitted divergence from common ways of thinking and writing, as well as the body of textual evidence that seems to back up his claims concerning his uniqueness.

\footnotetext{
${ }^{8}$ Note the structural similarity here to certain uses of $s h i$ 實 such as that of the Meng-Zi 4A27, which discusses “the fruits of" a number of virtues, for example 仁之實, 事親是也 (“the fruit of humanity is service to ancestors").
} 


\subsection{Explanatory Strength vs. Alternative Approaches}

Mou's most challenging objection comes through his appraisal of my interpretation as an explanation of the text along side his own, thus challenging my claim that my own pluralist interpretation of Wang is the best available way of making sense of the text. Mou argues that his account has greater explanatory force than the one I offer-and indeed if this is the case, it would constitute a decisive objection against my account.

Mou offers a number of considerations to demonstrate that his account of Wang's pluralist theory, based in what he calls "substantive perspectivism", has more explanatory power than the "second-order property" account I attribute to Wang. Some of these are related to his objections to my interpretation in 1-4 above, and some diverge from this.

Mou argues that his substantive perspectivist account of truth captures the pretheoretical basis of the folk understanding of truth better than the second-order account I attribute to Wang. I completely agree with Mou that Wang's account is meant as an elaboration of this folk concept (in his particular way), and that, insofar as constructing interpretations in the history of philosophy is concerned, that "philosophy should not be revisionary of our intuitive understanding or folk usage about the matters in question unless there are very strong theoretical or practical reasons in favor of revision" [164] $]^{9}$ As I argued above, however, I don't think that Wang's view was a radical revision of the folk understanding of $s h i$ 實 (though it was a revision), and that it was perfectly consistent with and continuous with earlier usage of the term and understandings of the concept.

Mou also argues that his substantive perspectivist approach, insofar as it serves as an elaboration on a pre-theoretic folk concept of truth, can better engage with other elaborations of this concept such as Tarski's, in such a way that each can benefit from the engagement. Tarski's account can be strengthened through taking into account features of the substantive perspectivist account of truth that Mou argues was adopted by Wang. This, I think, points toward a real point of tension in my own position concerning Wang Chong as well as my interpretive methodology in general. If it turns out that Mou's substantive perspectivist view captures a pre-theoretical sense of truth that Tarski also elaborated, it does seem that this would make the early Chinese and Tarski's views more "commensurable". This may lead to more fruitful engagement than would otherwise be possible if Wang or the early Chinese have some radically different conception of truth. The two conceptions of truth would be cooperative

\footnotetext{
${ }^{9}$ I accept this with some caveats: 1) in the history of philosophy, the intuitions we should look to respect are those we have reason to believe were their intuitions (that is, those of the authors of the texts we interpret), not our own; 2) I don't agree with this for philosophy in general outside of the realm of historical interpretation (if we are simply looking for the truth about things rather than what Wang Chong or some other philosopher thought), because we don't have reason to think intuitions are a good guide to truth. We have no choice but to begin with intuitions, but it's unclear to me we should resist revising concepts or theories on the basis of intuition rather than any other consideration, given our inability to show they actually track the truth, and our seeming evidence than in very many cases they not only do not track the truth, but indeed blind us to it. But this is a debate for another place.
} 
rather than be competing. Given that one of my interpretive goals is to further our understanding of the concept of truth in general, this might lend strength to an interpretation closer to Tarski or other views of truth influential today. On the other hand, faithfulness to texts and traditions can be a conflicting consideration. What if Wang and other early Chinese thinkers did have a radically different understanding of truth, including in its pre-theoretic form? In that case, it looks like my two interpretive aims conflict. Faithfulness to text and tradition in such a case would require advancement of interpretations that do not easily contribute to contemporary debates or understandings, and vice versa. Though in many (perhaps most) cases a balance between these two considerations can be maintained, there may be some cases in which this is not possible. And in such cases, which interpretive guide do we privilege?

While I think my interpretation of Wang's concept of $s h i$ 實 does indeed capture a pre-theoretical understanding of the term, I'm not yet sure to what extent this pretheoretical understanding (insofar as we can make sense of one) matches that of Tarski or other western philosophers. One problem with making claims about pretheoretical understandings of certain terms is that as soon as we start describing them, we're into the realm of theory. Generally we cannot do much more than describe usage and perhaps conceptual intuitions when we attempt to describe "pretheoretical" understandings. But then if this is the case, it looks like an enormous number of theories will be compatible with pre-theoretical notions, as long as they can make sense of folk usage. Part of the issue here perhaps is with the label "pretheoretical". I suspect Mou means by this a folk concept rather than something literally pre-theoretical, especially if we take the position that a concept is just a particular role in a theory (which of course is controversial, but still presses the problem). The more disconnected from theory the folk understanding of truth (or shi 實) is, the more compatible any theoretical account of it will be with this understanding. So it may turn out (indeed I think it should turn out) that every theoretical account of truth is consistent with the folk sense of truth (insofar as there is folk sense of truth, rather than folk senses of truth). In order to cohere with the folk understanding, these theories need only make sense of the usage of truth-terms and perhaps general intuitions about truth such as the "correspondence intuition" (similar to Mou's ATNT). And Wang Chong's concept of shi 實 respects the correspondence intuition. A statement that has the property of having properties we do and should seek is a statement that represents "the way things are". What we do and should seek is one way of construing "the way things are". What would fail to be sufficiently basic is if Wang were to make the claim that we do and should seek certain properties because they represent the way things are. But, I argue, he does not hold this at all. What we do and should seek is basic. There is no further fact about the connection between what we do and should seek and "the way things (actually) are." Arguably, the general acceptance of this intuition in early China is one reason the problems of representationalism and skepticism that became endemic in western philosophy never took hold in early Chinese thought. 
This view, of course, sacrifices my second aim in interpretation (usefulness for contemporary debates) in the name of the first (faithfulness to text and tradition). But perhaps the tradeoff is justified here. Even though such a view, as Brons points out in his comments, radically challenges positions concerning normativity and truth in general held by contemporary philosophers, it can still contribute to contemporary debates in a number of ways. First - it can challenge us to rethink our basic assumptions about truth. Perhaps some of the problems of our theories of truth are due to fundamentally flawed ways of thinking about these concepts. Consideration of very different conceptions may help us see these flaws. Second-even though such a conception of truth might be very different than those dominant in the west (and I'm actually not yet convinced that this is so, though neither do I have any good argument that it's not), it still may be able to contribute to contemporary debates in ways beyond simply presenting a challenge or alternative. There are always ways of integrating helpful elements of radically different theories into one's own, given that they are theories of the same thing. Of course, how radically different they are raises the difficult question of whether they in fact are theories of the same thing. That is, are early Chinese theories of truth like that of Wang Chong, if I am right about their very different nature, actually theories of truth at all? I think we have good reason to think that they are, in part due to the basic and abstract nature of the concept of truth, but that is an argument for a different place.

\section{REFERENCES}

Brons, Lajos (2015), "Wang Chong, Truth, and Quasi Pluralism", Comparative Philosophy, 6 (1): 129-148

McLeod, Alexus (2007), “A Reappraisal of Wang Chong's Critical Method Through the Wenkong Chapter", Journal of Chinese Philosophy, 34 (4): 581-596

McLeod, Alexus (2011), "Pluralism About Truth in Early Chinese Philosophy: A Reflection on Wang Chong's Approach", Comparative Philosophy, 2 (1): 38-60

Mou, Bo (2015), "Rooted and Rootless Pluralist Approaches to Truth: Two Distinct Interpretations of Wang Chong's Account", Comparative Philosophy, 6 (1): 149167

Nylan, Michael (1997), "Han Classicists Writing in Dialogue About Their Own Tradition", Philosophy East and West, 47 (2): 133-188.

Sher, Gila. (2015), "Truth as Composite Correspondence", in Achourioti, Galinon, Martinez-Fernandez, and Fujimoto (eds), Unifying the Philosophy of Truth (Dordrecht: Springer).

Wright, Crispin (2013), "A Plurality of Pluralisms", in Pederson and Wright (eds). Truth and Pluralism: Current Debates (Oxford: Oxford University Press), 123153. 